\title{
Significado do trabalho nos setores público e privado*
}

\author{
Maria Aparecida Gouvêa ${ }^{1}$ \\ Sérgio Hideo Kubo ${ }^{2}$ \\ Daielly Melina Nassif Mantovani ${ }^{3}$ \\ Universidade de São Paulo
}

Essa pesquisa teve como objetivo investigar os fatores associados ao significado do trabalho e os indicadores relevantes no ambiente empresarial de acordo com os funcionários dos setores público e privado. A partir de uma amostra de 304 profissionais pertencentes a estes setores, foi elaborado um modelo inicial que não mostrou resultados estatísticos satisfatórios e foi substituído por um modelo alternativo que apresentou melhor qualidade de ajuste aos dados. O estudo revelou que, para a amostra geral e para o setor público, o significado do trabalho se reflete, na ordem, na centralidade do trabalho, objetivos e resultados valorizados e por último, nas normas sociais. Há uma inversão na segunda e terceira colocação deste ranking quando se focaliza o setor privado. Com base neste estudo, o conhecimento das componentes do significado do trabalho na vida das pessoas pode contribuir para uma melhor gestão dos recursos humanos no contexto empresarial.

Palavras-chave: Significado do trabalho - Centralidade - Objetivos e resultados - Normas sociais.

This research was developed in order to investigate the factors associated with the meaning of work and the relevant indicators in business environment in accordance with the staff of public and private sectors. From a sample of 304 professionals belonging to these sectors, an initial model has been prepared, which did not show satisfactory statistical results and was replaced by one alternative model which presented better goodness of fit to data. The study revealed that, considering the general sample and public sector, the meaning of work is reflected, in the order, in the centrality of work, objectives and results valued and finally, in social norms. There is a reversal in the second and third placing of this ranking when it focuses on the private sector. Based on this study, the knowledge of the components of the meaning of work in the lives of people can contribute to a better human resources management in the business context.

Keywords: Work meaning - Centrality Objectives and results - Social norms.

\footnotetext{
"Meaning of work in public and private sectors.

${ }^{1}$ Faculdade de Economia, Administração e Contabilidade, FEA/USP. Endereço para correspondências: Avenida Professor Luciano Gualberto, 908, São Paulo, SP, 05508-010 (magouvea@usp.br).

${ }^{2}$ Faculdade de Economia, Administração e Contabilidade, FEA/USP. Endereço para correspondências: Avenida Professor Luciano Gualberto, 908, sala G162, São Paulo, SP, 05508-010 (shkubo2@gmail.com).

${ }^{3}$ Faculdade de Economia, Administração e Contabilidade, FEA/USP. Endereço para correspondências: Avenida Professor Luciano Gualberto, 908, sala G162, São Paulo, SP, 05508-010 (daimantovani@gmail.com).
} 


\title{
1. Introdução
}

\begin{abstract}
A psicologia organizacional inicialmente preocupava-se somente com o indivíduo dentro da organização. Hoje, a psicologia organizacional é considerada um campo de estudos interdisciplinar, onde são estudadas as interações do indivíduo com a antropologia, a sociologia e a ciência política, entre outros, levando a uma compreensão abrangente dos fenômenos que ocorrem dentro do ambiente organizacional. $\mathrm{O}$ estudo da psicologia organizacional coloca o indivíduo dentro do sistema organizacional, observando-se o seu comportamento e o seu desenvolvimento nesse ambiente.
\end{abstract}

\begin{abstract}
Quando uma pessoa pensa em trabalho, geralmente pensa em emprego. Porém, o trabalho não é somente um emprego. É muito mais. Embora seja por meio dele que se consiga a subsistência básica e condições materiais para uma vida decente, não tem somente essa função. É, acima de tudo, uma atividade por meio da qual um indivíduo se inclui no mundo, cria relacionamentos, usa seus talentos, aprende e desenvolve sua identidade e o sentimento de fazer parte (MORIN, 2004; p. 3).
\end{abstract}

Para adequar as características do trabalho às necessidades individuais ou às necessidades de um grupo é preciso conhecer o que é valorizado por essas pessoas. Os cientistas sociais acreditam que conhecendo as facetas do trabalho é possível clarificar a satisfação e a motivação no trabalho (SOARES, 1992).

O servidor público no Brasil tem características diferenciadas, considerando-se o seu relacionamento com o seu empregador. Além disso, seu relacionamento com o que se poderia chamar de cliente é específico e diferenciado se comparado com o de empresas privadas. Portanto, é possível entender que o significado do trabalho se apresenta também diferenciado para os indivíduos dos setores público e privado, inclusive em relação a outros países em que esse relacionamento é tratado pelos legisladores constitucionais de forma distinta.

Considerando-se as diferenças estruturais entre o setor público e o setor privado no Brasil, em termos de processo de seleção dos colaboradores, admissão e demissão, avaliação de desempenho e progressão de carreira entre outros aspectos, é possível supor que o trabalho tenha significados diferentes para ambos em decorrência dessas diferenças estruturais.

Assim, o objetivo deste estudo é a identificação dos aspectos mais associados ao significado do trabalho em uma população, em que aproximadamente a metade é composta por empregados do setor público e outra metade por outros setores (privados). Pretende-se também verificar se há diferença nos 


\section{Significado do trabalho nos setores público e privado}

M.A. Gouvêa, S.H. Kubo \& D.M.N. Mantovani

indicadores mais relevantes no ambiente de trabalho de acordo com os empregados de cada setor, no que tange os aspectos da relevância do trabalho para ambos os setores (o trabalho possui papel mais importante para o setor público ou privado?), objetivos que se estabelecem para o trabalho (realização pessoal, remuneração, status na sociedade, segurança) e normatização social do trabalho (direitos e deveres associados ao trabalho).

\section{Fundamentação Teórica}

Na revisão bibliográfica serão abordados conceitos sobre o trabalho e os construtos usados em modelagens sobre o sentido do trabalho na vida das pessoas. Em seguida, os principais modelos desenvolvidos sobre este tema serão comentados. Posteriormente será focalizado o trabalho na administração pública.

\subsection{O trabalho}

O trabalho é conceituado como "o conjunto das ações que o homem, com uma finalidade prática, com a ajuda do cérebro, das mãos, de instrumentos ou de máquinas, exerce sobre a matéria, ações que, por sua vez, reagindo sobre o homem, modificam-no" (FRIEDMAN \& NAVILLE, 1973; apud SIEBRA, 2000; p. 40). Segundo Albornoz (apud FONSECA, 2000), o trabalho se torna mais nítido, quanto mais clara for a intenção e a direção do esforço aplicado. Nesse contexto, trabalho possui o significado de um esforço afirmado e desejado, para a realização de objetivos.

$\mathrm{Na}$ antiguidade, segundo Grazia (2000), os gregos clássicos queriam ser sábios e, para ser sábio, era necessário ter ócio. Segundo Gomes (2008; p. 21), o ócio para os gregos significava um exercício em forma elevada, atribuída à alma racional, sendo que os "tesouros do espírito eram frutos do ócio". Dessa forma, o ócio tinha o sentido de desprendimento das tarefas servis, condição para a contemplação, a reflexão e a sabedoria. Para cada cidadão ocioso, havia a necessidade de quatro escravos para provê-lo em suas necessidades. Os escravos trabalhavam na agricultura, em minas e em casas ricas. O homem livre, por sua vez, entre outras profissões, podia ser agricultor, sapateiro, carpinteiro ou comerciante.

Com o declínio da civilização grega e ascensão romana, ainda influenciada pela cultura helênica, houve a difusão do latim e dos valores culturais de Roma nas numerosas províncias conquistadas. Havia o ensinamento de direito e deveres dentro de valores romanos de justiça e disciplina, pois a educação de Roma era, antes de mais nada, utilitária e militarista (GOMES, 2008). 
Na idade média, o trabalho, na visão do catolicismo, era uma oportunidade de redenção divina aos pecados cometidos e, na visão do protestantismo, era uma forma de obter riqueza, servindo a Deus, na medida em que mantinha o ócio e a luxúria à distância (CARMO, 2001). A partir do século XIX, após a introdução do modo capitalista de produção, difundiu-se a idéia de que a riqueza de um país dependia, efetivamente, do trabalho, que, segundo Gomes (2008), se transformou em um elemento fundamentalmente integrador da sociedade.

\subsection{Construtos e a compreensão do sentido do trabalho}

Na pesquisa bibliográfica sobre modelos desenvolvidos para o entendimento do significado do trabalho, constatou-se predomínio de alguns construtos estudados pelos pesquisadores dedicados a este tema. Antes de se focalizarem os modelos, julgou-se pertinente a menção aos construtos neles incluídos: centralidade do trabalho, normas sociais do trabalho e resultados e objetivos valorizados do trabalho.

O conceito de centralidade do trabalho está relacionado com a importância relativa do trabalho na vida de uma pessoa. Segundo o estudo MOW Meaning of Working International Research Team (1987), o construto da centralidade do trabalho é composto por dois componentes teóricos que são: a orientação sobre o valor do papel do trabalho na vida e a esfera da vida preferida na decisão do comportamento de cada pessoa. Analogamente, Son (2006) decompõe a centralidade do trabalho em envolvimento com o trabalho e relevância do trabalho. Segundo Harpaz e Fu (2002; p. 641), "o trabalho é uma das atividades mais básicas e importantes para pessoas na sociedade moderna". O trabalho tem sido classificado, geralmente, como a segunda mais importante esfera na vida de uma pessoa, perdendo somente para a família.

Normas sociais do trabalho consistem em orientações normativas percebidas pelos indivíduos como justas, eqüitativas e socialmente legítimas (PÉREZGONZÁLES \& VILELA, 2005). Para Son (2006; p. 46), normas sociais orientadas a deveres representam a "crença de que todas as pessoas têm o dever ou responsabilidade para as unidades sociais através do trabalho". Porém, normas sociais orientadas aos direitos são "direitos individuais admitidos como obrigações sociais".

Segundo Pérezgonzáles e Vilela (2005), os resultados e objetivos valorizados do trabalho são as funções que se recebem do trabalho e que têm valor para o indivíduo. Podem ser destacados: I) função de fonte de renda do trabalho, geralmente considerado o mais importante; II) função intrínseca do trabalho, quando o trabalho é interessante e satisfatório para os indivíduos; III) função interpessoal do trabalho, como meio para contatos interessantes com outras pessoas; 


\section{Significado do trabalho nos setores público e privado}

M.A. Gouvêa, S.H. Kubo \& D.M.N. Mantovani

IV) função de servir à sociedade pelo trabalho, V) função de ocupação do tempo com o trabalho; vi) função de fornecer status e prestígio pelo trabalho (MOW, 1987).

\subsection{Modelos estruturais}

Nesta seção será apresentado um resumo do modelo de MOW - Meaning of Working International Research Team (1987), considerado uma das principais referências em estudos sobre o significado do trabalho. Em seguida, haverá menções de outros modelos também relevantes neste contexto.

\subsubsection{MOW - Meaning of Working International Research Team (1987)}

No estudo realizado pelo MOW - Meaning of Working International Research Team em países industrializados fez-se um levantamento de informações concernentes ao significado do trabalho em uma amostra de 14.700 indivíduos, no período compreendido entre 1978 e 1984, em oito países (Bélgica, Inglaterra, Alemanha, Israel, Japão, Holanda, Estados Unidos da América e Iugoslávia). Foram abordados três níveis de relação com a questão do trabalho na vida das pessoas: variáveis condicionais (circunstâncias pessoais e familiares, tais como educação, religião, atividade do cônjuge; atividade atual e histórico da carreira, tais como cargo, tempo de casa, tempo sem emprego; ambiente econômico e social, tais como origem - onde viveu até os 14 anos e onde vive atualmente, quantidade de pessoas que sustenta, participação em igreja e sindicatos), variáveis centrais (centralidade do trabalho; normas sociais acerca do trabalho; resultados valorizados do trabalho; objetivos do trabalho; papel do trabalho) e conseqüências (expectativas subjetivas sobre trabalho no futuro, por exemplo, a importância que o trabalho teria no futuro; resultados objetivos do trabalho, tais como oportunidade de evolução).

Os construtos encontrados no modelo final pela equipe MOW, após a execução de análise fatorial exploratória, foram: I) Centralidade do trabalho, II) Normas sociais orientadas para os direitos, III) Normas sociais orientadas para os deveres, IV) Função econômica do trabalho, V) Resultado intrínseco ou expressivo, VI) Contato interpessoal pelo trabalho. Esses construtos ajudam a compreender o valor do trabalho para o indivíduo, já que o trabalho representa um papel fundamental na vida do ser humano, e pode ser entendido como uma série de atividades realizadas com intuito de se obter um resultado útil (MORIN, 2004). No contexto organizacional, o estudo do significado do trabalho auxilia a encontrar incoerências entre as expectativas do trabalhador acerca de sua função e a real função exercida. 
Tais incoerências, na prática podem prejudicar o desempenho do indivíduo, desmotivá-lo e reduzir seu comprometimento com o trabalho. Portanto, ao se identificarem inconsistências sobre o significado do trabalho, é possível redefinir o desenho das funções de forma a se atribuir significado relevante ao trabalho, o que elevará o clima organizacional e impactará na qualidade e perícia dos produtos e serviços ofertados à sociedade e por conseguinte, nos resultados organizacionais.

\subsubsection{Outros modelos sobre significado do trabalho}

Na busca de diferenças de percepção sobre o significado do trabalho, de acordo com estratos profissionais e países específicos, relevantes estudos podem ser destacados: Kanungo (1982), Soares (1992), Lundberg e Peterson (1994), Bastos (1995), Harpaz e Fu (2002), Pérezgonzález e Vilela (2005) e Son (2006).

Kanungo (1982) abordou a centralidade do trabalho, focalizando o trabalho atual e o trabalho como conceito geral. Concluiu que o trabalho atual está mais relacionado com a satisfação das necessidades pessoais enquanto o trabalho em geral, ou a centralidade do trabalho, representa o quanto o trabalho é valorizado, sendo função de condicionantes culturais e sociais.

O modelo de MOW (1987) serviu como referência para os estudos realizados a partir da década de 90, os quais fizeram adaptações dos construtos deste modelo. O modelo de Soares (1992) considerou variáveis condicionais (categoria ocupacional) e centrais (centralidade do trabalho, da família e da religião; resultados sociais e resultados econômicos; objetivos intrínsecos e objetivos extrínsecos valorizados). Lundberg e Peterson (1994) consideraram em seu modelo as variáveis centrais: centralidade do trabalho, normas sociais e objetivos valorizados. Bastos (1995) considerou em seu estudo: centralidade do trabalho, normas sociais e resultados e objetivos valorizados.

Harpaz e Fu (2002) usaram os mesmos indicadores de MOW (1987), agrupados de forma diferente nos construtos: centralidade do trabalho, orientação econômica, relacionamento interpessoal, orientação expressiva, normas acerca dos direitos sociais e normas acerca das obrigações sociais. Pérezgonzález e Vilela (2005) encontraram duas dimensões, sendo um domínio denominado de Motivos e valores (papéis do trabalho, conforto e expressivo) e o outro de Crenças normativas (centralidade, deveres e direitos e contribuição social). Son (2006) encontrou três padrões de significado de trabalho: aspectos financeiros e status sociais; relacionamento social e aspectos psicológicos; e normas sociais e valor do trabalho. 


\section{Significado do trabalho nos setores público e privado}

M.A. Gouvêa, S.H. Kubo \& D.M.N. Mantovani

Estes estudos proporcionaram sustentação teórica para a elaboração do modelo proposto nesse artigo a ser explicitado na seção 3.3. A Tabela 1 apresenta os indicadores para centralidade do trabalho, normas sociais e objetivos e resultados valorizados encontrados na literatura pesquisada. A coluna "MP" refere-se ao modelo proposto neste estudo.

Tabela 1

Construtos e indicadores utilizados na definição do significado do trabalho.

\begin{tabular}{|c|c|c|c|c|c|}
\hline $\begin{array}{c}\text { Construto } \\
2\end{array}$ & Construto 1 & Variável & Descrição & $\begin{array}{c}\text { Modelo } \\
\text { proposto }\end{array}$ & Referência \\
\hline \multirow{10}{*}{$\begin{array}{l}\text { Centrali- } \\
\text { dade do } \\
\text { trabalho }\end{array}$} & \multirow{2}{*}{$\begin{array}{c}\text { Centrali- } \\
\text { dade do } \\
\text { trabalho } \\
\text { MOW }\end{array}$} & 60 & $\begin{array}{l}\text { Importância do trabalho em } \\
\text { termos absolutos }\end{array}$ & MP & 2345678 \\
\hline & & $104 a$ & Importância relativa do trabalho & MP & 2345678 \\
\hline & \multirow{8}{*}{$\begin{array}{c}\text { Centrali- } \\
\text { dade do } \\
\text { trabalho } \\
\text { Kanungo }\end{array}$} & 01 & $\begin{array}{l}\text { Trabalho como causa das coisas } \\
\text { importantes da vida }\end{array}$ & & 17 \\
\hline & & 03 & Trabalho como objetivo de vida & MP & 17 \\
\hline & & 05 & Ênfase no trabalho & MP & 17 \\
\hline & & 07 & Envolvimento com o trabalho & MP & 17 \\
\hline & & 08 & Importância do trabalho na vida & & 17 \\
\hline & & 11 & Trabalho como sentido da vida & MP & 17 \\
\hline & & 12 & $\begin{array}{l}\text { Trabalho como a coisa mais } \\
\text { importante }\end{array}$ & & 17 \\
\hline & & 14 & $\begin{array}{l}\text { Trabalho deveria ser menos } \\
\text { importante }\end{array}$ & & 17 \\
\hline \multirow{10}{*}{$\begin{array}{l}\text { Normas } \\
\text { sociais }\end{array}$} & \multirow{5}{*}{$\begin{array}{c}\text { Normas } \\
\text { orienta- } \\
\text { das a } \\
\text { direitos }\end{array}$} & 15 & $\begin{array}{l}\text { Direito a treinamento para a } \\
\text { função }\end{array}$ & MP & 2345678 \\
\hline & & 17 & $\begin{array}{l}\text { Direito a formação escolar para } \\
\text { um bom emprego }\end{array}$ & & 2345678 \\
\hline & & 19 & $\begin{array}{l}\text { Direito a opinar sobre métodos e } \\
\text { decisões no trabalho }\end{array}$ & MP & 2345678 \\
\hline & & 21 & $\begin{array}{l}\text { Direito a trabalho interessante e } \\
\text { significativo }\end{array}$ & MP & 2345678 \\
\hline & & 23 & Direito ao emprego & & 234578 \\
\hline & \multirow{5}{*}{$\begin{array}{c}\text { Normas } \\
\text { orienta- } \\
\text { das a } \\
\text { deveres }\end{array}$} & 16 & $\begin{array}{l}\text { Contribuir à sociedade } \\
\text { trabalhando }\end{array}$ & MP & 2345678 \\
\hline & & 18 & Dever de economizar & MP & 234567 \\
\hline & & 20 & $\begin{array}{l}\text { Dever de pensar em melhorias no } \\
\text { trab. }\end{array}$ & & 234578 \\
\hline & & 22 & $\begin{array}{l}\text { Dever de aceitar trabalho } \\
\text { monótono desde que bem pago }\end{array}$ & & 234578 \\
\hline & & 24 & Dar valor ao trabalho & MP & 235678 \\
\hline
\end{tabular}




\begin{tabular}{|c|c|c|c|c|c|}
\hline \multirow{17}{*}{$\begin{array}{l}\text { Objetivos } \\
\mathrm{e} \\
\text { resultados } \\
\text { valorizados }\end{array}$} & \multirow{11}{*}{$\begin{array}{l}\text { Objeti- } \\
\text { vos } \\
\text { valoriza- } \\
\text { dos do } \\
\text { trabalho }\end{array}$} & 38 & Aprender coisas novas & & 234578 \\
\hline & & 39 & Ascensão ou promoção & & 234578 \\
\hline & & 40 & Autonomia & MP & 234578 \\
\hline & & 41 & Tarefa adequada à capacidade & MP & 234578 \\
\hline & & 42 & Variedade & MP & 2345678 \\
\hline & & 43 & Estabilidade no emprego & MP & 234578 \\
\hline & & 44 & Ambiente físico de trabalho & & 234578 \\
\hline & & 45 & Bom relacionamento interpessoal & MP & 2345678 \\
\hline & & 46 & Trabalho interessante & MP & 2345678 \\
\hline & & 47 & Bom salário & MP & 2345678 \\
\hline & & 48 & Horário de trabalho conveniente & & 234578 \\
\hline & \multirow{6}{*}{$\begin{array}{l}\text { Resulta- } \\
\text { dos } \\
\text { valoriza- } \\
\text { dos do } \\
\text { trabalho }\end{array}$} & 02 & Renda & & 23567 \\
\hline & & 04 & Contatos interessantes & & 23567 \\
\hline & & 06 & Função serviço social do trabalho & & 2357 \\
\hline & & 09 & Status e prestígio & & 2357 \\
\hline & & 10 & $\begin{array}{l}\text { Trabalho como algo, em si, } \\
\text { interessante e satisfatório }\end{array}$ & & 23567 \\
\hline & & 13 & Mantém ocupado & & 2357 \\
\hline
\end{tabular}

Notas: (1) Kanungo (1982); (2) MOW (1987); (3) Soares (1992); (4) Lundberg e Peterson (1994); (5) Bastos (1995); (6) Harpaz e Fu (2002); (7) Pérezgonzález e Vilela (2005); (8) Son (2006).

\subsection{O trabalho na administração pública}

Embora este estudo não esteja restrito à análise do significado do trabalho no âmbito do setor público, esta seção tem por objetivo destacar algumas informações sobre a evolução histórica neste contexto para maior embasamento na etapa de análise dos resultados, quando os dados forem filtrados para este segmento. A administração pública no Brasil, segundo Bresser-Pereira (2007, p. 11), pode ser dividida em três fases, como indicado na Tabela 2.

Na primeira fase, referente ao século XIX, a sociedade caracteriza-se por ser patriarcal e mercantil por ser dominada pelo latifúndio agro-exportador e pelos comerciantes locais, que não incorporam ainda as idéias de progresso técnico e produtividade, enquanto o Estado conta com a participação importante de uma burocracia patrimonial. Na segunda fase, a partir de 1930, quando começa a Revolução Industrial brasileira, a sociedade passa a ser industrial, porque, agora, os empresários industriais tornam-se dominantes. No Estado nacional-desenvolvimentista, dominante entre 1930 e 1980, a classe dirigente é caracterizada por uma forte aliança entre a burguesia industrial e a burocracia pública, e o período é marcado por um grande desenvolvimento econômico. Seu sentido político maior é a transição do autoritarismo para a democracia. Na terceira fase, a partir de 1990, 
a modernização da administração pública no Brasil passa, principalmente, pela Reforma Gerencial ou Reforma da Gestão Pública de 1996. Assume caráter crescentemente gerencial, onde a ênfase é a eficiência, voltada para a realização eficiente das tarefas e, portanto, para a redução dos custos e o aumento da qualidade dos serviços, independentemente das normas e rotinas, que continuam necessárias, mas são flexibilizadas. Essa reforma está apoiada na proposta de administração pública gerencial, como uma resposta à grande crise do Estado dos anos 1980 e à globalização da economia - dois fenômenos que estão impondo, em todo o mundo, a redefinição das funções do Estado e da sua burocracia (BRESSER-PEREIRA, 2007).

Tabela 2

Formas de estado e de administração no Brasil, séculos XIX e XX.

\begin{tabular}{l|c|c|c}
\hline CATEGORIA & $\mathbf{1 8 2 1 - 1 9 3 0}$ & $\mathbf{1 9 3 0 - 1 9 8 5}$ & $\mathbf{1 9 9 0}$ - dias atuais \\
\hline \hline Estado/sociedade & $\begin{array}{c}\text { Patriarcal- } \\
\text { dependente }\end{array}$ & $\begin{array}{c}\text { Nacional- } \\
\text { desenvolvimentista }\end{array}$ & Liberal-dependente \\
\hline Regime político & Oligárquico & Autoritário & Democrático \\
\hline Classes dirigentes & $\begin{array}{c}\text { Latifundiários e } \\
\text { burocracia } \\
\text { patrimonial }\end{array}$ & $\begin{array}{c}\text { Empresários e } \\
\text { burocracia pública }\end{array}$ & $\begin{array}{c}\text { Agentes financeiros } \\
\text { e rentistas }\end{array}$ \\
\hline Administração & Patrimonial & Burocrática & Gerencial \\
\hline \hline
\end{tabular}

Fonte: Adaptado de Bresser-Pereira (2007)

O governo do Estado de São Paulo é constituído de vinte secretarias e da Procuradoria Geral, que no conjunto formam a administração centralizada; por sua vez, a administração descentralizada compõe-se de vinte e quatro autarquias, dezenove empresas e dezessete fundações. Embora durante o período de 1995 a 2003 tenha havido uma quantidade expressiva de privatizações, com a conseqüente transferência de pessoal dos órgãos privatizados para a iniciativa privada, a despesa de pessoal cresceu $182 \%$ em termos nominais, enquanto a quantidade de servidores diminuiu em 3,7\%. Há também uma preocupação da administração devido à elevada média etária, com tendência ao crescimento do número de aposentadorias e certas inadequações, como a falta de pessoal em áreas estratégicas e o excesso em atividades que, automatizadas pela tecnologia da informação, poderiam ter um quadro de pessoal bem menor (SECRETARIA DE GESTÃO PÚBLICA, 2008).

No período de 2003 a 2006, há um diagnóstico, da administração, sobre a falta de cultura gerencial voltada à gestão de pessoal e de incentivos efetivos para a melhoria do desempenho que pode ser resumido como segue: "Processos de trabalho burocratizados e inúteis absorvem grandes contingentes de servidores, cuja contribuição poderia ser muito mais eficiente em outras atividades" (SECRETARIA DE GESTÃO PÚBLICA, 2008). 


\section{UMANAS}

Tendo em vista o diagnóstico da força de trabalho paulista, para o período 2003 a 2006, foi apresentada uma proposta de objetivos e estratégias para a política de recursos humanos do governo do Estado de São Paulo, que tem os seguintes itens: a) renovar a força de trabalho, b) reestruturar e remunerar por desempenho e seguindo padrões de mercado, c) atualizar, qualificar, motivar, dar empowerment e responsabilizar a força de trabalho, d) adequar os recursos organizacionais para a gestão dos recursos humanos (SECRETARIA DE GESTÃO PÚBLICA, 2008).

Para conseguir ter bom êxito no item c, é importante ter um diagnóstico preciso das condições atuais nos quesitos apresentados e avaliar os valores mais importantes, ou seja, o significado do trabalho para os funcionários.

\section{Aspectos Metodológicos}

Os procedimentos metodológicos empregados neste estudo são descritos nesta seção.

\subsection{Tipo de pesquisa}

Realizou-se uma pesquisa descritiva exploratória no primeiro semestre de 2009 , que possibilitou relacionar variáveis e validar construtos do modelo usado como referência para este estudo.

\subsection{População, amostragem e coleta de dados}

A população de interesse neste estudo é geral e circunscrita aos residentes no Brasil. A coleta de dados foi feita por meio de um levantamento mediante questionário armazenado em um site pré-determinado na internet. O questionário tem como base o modelo descrito na seção 3.3. Utilizou-se amostragem não probabilística devido à inexistência de um cadastro de e-mails da população geral para o sorteio dos participantes da pesquisa. Foram acessados e-groups dos atuais e ex-alunos da Faculdade de Economia, Administração e Contabilidade da Universidade de São Paulo (FEA-USP), que estão inseridos no mercado de trabalho e outros e-groups de funcionários públicos. A amostra efetiva deste estudo foi de 304 participantes. 


\subsection{Modelo desenvolvido neste estudo}

O modelo de pesquisa adotado pode ser considerado fusão do modelo de Son (2006) com o modelo final do MOW (1987).

No modelo proposto, há uma adaptação do modelo final do MOW (1987) com a fusão dos três construtos: resultados valorizados extrínsecos; resultados valorizados intrínsecos; contatos interpessoais em um construto que foi denominado como resultados e objetivos valorizados intrínsecos e extrínsecos. Houve também uma adaptação do modelo de Son (2006), com a separação das normas sociais, único no modelo de Son (2006), em dois construtos: normas sociais orientadas aos direitos e normas sociais orientadas aos deveres.

Os construtos do modelo para pesquisa são: a) centralidade do trabalho; b) normas acerca dos direitos sociais; c) normas acerca dos deveres sociais; d) resultados e objetivos valorizados intrínsecos e extrínsecos (Figura 1). A cada construto são associados indicadores, resultados desses construtos, que terão questões correspondentes no questionário aplicado.

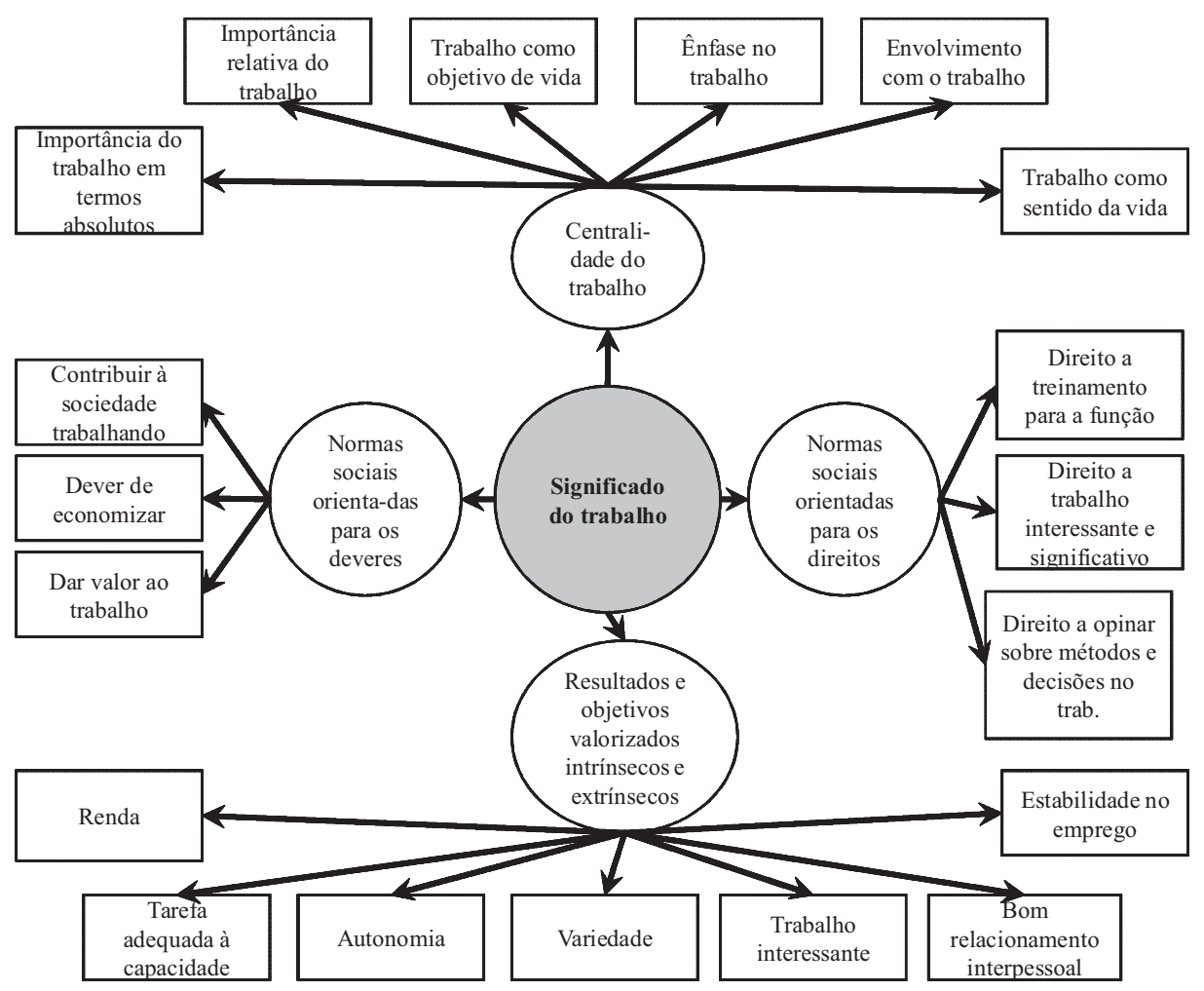

Figura 1

Construtos e variáveis do modelo teórico estudado. 
UMANAS

Para o construto centralidade do trabalho foram incluídos, além dos indicadores do MOW (1987), outros quatro correspondentes a questões de Kanungo (1982). Com base no modelo proposto, são enunciadas as seguintes hipóteses:

$\mathrm{H}_{1}$ : A centralidade no trabalho é o aspecto mais relevante na composição do construto significado do trabalho.

$\mathrm{H}_{2}$ : Os objetivos e resultados valorizados são o segundo aspecto mais relevante na composição do construto significado do trabalho.

$\mathrm{H}_{3}$ : As normas sociais são o terceiro aspecto mais relevante na composição do construto significado do trabalho.

$\mathrm{H}_{4}$ : A centralidade no trabalho é o aspecto mais relevante na composição do construto significado do trabalho no setor público.

$\mathrm{H}_{5}$ : Os objetivos e resultados valorizados são o segundo aspecto mais relevante na composição do construto significado do trabalho no setor público.

$\mathrm{H}_{6}$ : As normas sociais são o terceiro aspecto mais relevante na composição do construto significado do trabalho no setor público.

$\mathrm{H}_{7}$ : A centralidade no trabalho é o aspecto mais relevante na composição do construto significado do trabalho em outros setores.

$\mathrm{H}_{8}$ : Os objetivos e resultados valorizados são o segundo aspecto mais relevante na composição do construto significado do trabalho em outros setores.

$\mathrm{H}_{9}$ : As normas sociais são o terceiro aspecto mais relevante na composição do construto significado do trabalho em outros setores.

\subsection{Técnica de análise dos resultados}

Para se testar o modelo do estudo, aplicou-se a modelagem de equações estruturais (MEE, ou Structural Equation Modeling).

Nesta técnica, os construtos são freqüentemente tratados por variáveis latentes (VL), em razão de não poderem ser medidos diretamente, e sim, por meio de um ou mais indicadores (Hair Jr. et al., 2005). No modelo do estudo há quatro VLs de primeira ordem (centralidade, normas orientadas para deveres, normas orientadas para direitos e resultados e objetivos valorizados) e uma VL de segunda ordem (significado do trabalho).

Utilizou-se o método de estimação Partial Least Squares (PLS) por sua simplicidade e flexibilidade quanto à distribuição dos dados e ao tamanho amostral (RINGLE et al., 2005). 


\section{Significado do trabalho nos setores público e privado}

M.A. Gouvêa, S.H. Kubo \& D.M.N. Mantovani

A confiabilidade dos indicadores em cada construto (VL de primeira ordem) do modelo proposto (MP) para este estudo é a avaliação do grau de consistência entre múltiplas medidas de uma variável (HAIR Jr. et al., 2005). Neste trabalho avaliou-se a confiabilidade interna, cujo objetivo é verificar se os indicadores individuais da escala medem o mesmo construto. A medida mais utilizada é o Alfa de Cronbach. Uma crítica ao Alfa de Cronbach é que este aumenta com o aumento do número de indicadores (HAIR Jr. et al., 2005); logo, escalas com muitos indicadores devem ser vistas com cautela. Uma alternativa ao Alfa de Cronbach é a Confiabilidade Composta.

A validade das escalas se refere a quanto o processo de medição está isento de erros amostrais e erros não amostrais (KINNEAR \& TAYLOR, 1996; apud NAKAGAWA, 2008), tendo sido avaliada neste estudo por dois métodos: método 1 - validade convergente: dada pela AVE (variância média extraída): variância capturada pelo construto em relação à variância devido a erros de medida. (FORNELL \& LARCKER, 1981); uma medida alternativa é a das cargas dos indicadores de uma VL, que devem ter valores acima de 0,7 e ser bem maiores que em outras VLs (CHIN, 1998); método 2 - validade discriminante: satisfeita se o valor da raiz quadrada da AVE for maior que os valores das correlações com as demais VLs (FORNELL \& LARCKER, 1981); uma medida alternativa é verificar a matriz de cargas ou cross-loadings (CHIN, 1998), cujos valores devem ser bem superiores nas próprias VLs do que para as demais VLs.

Analisou-se também a medida de qualidade de ajuste do modelo: Goodness-of-fit (GoF), que mede quanto da variância é explicada pelo modelo (TENENHAUS et al., 2005; apud ZWICKER et al., 2008).

\section{Análise dos resultados}

\subsection{Perfil da amostra}

A idade média é de aproximadamente 43 anos e há a predominância de respondentes casados, do sexo masculino, com pouco contato com religião e de formação superior. Quanto à classificação por administração pública e privada, há um equilíbrio com respectivamente 159 e 145 respondentes.

Os integrantes da amostra também declararam a importância relativa do trabalho em relação às outras esferas da vida. $O$ trabalho é a segunda esfera mais importante, com $25 \%$ de menções, aparecendo família em primeiro, com percentual de $54 \%$ (Figura 2). 
UMANAS

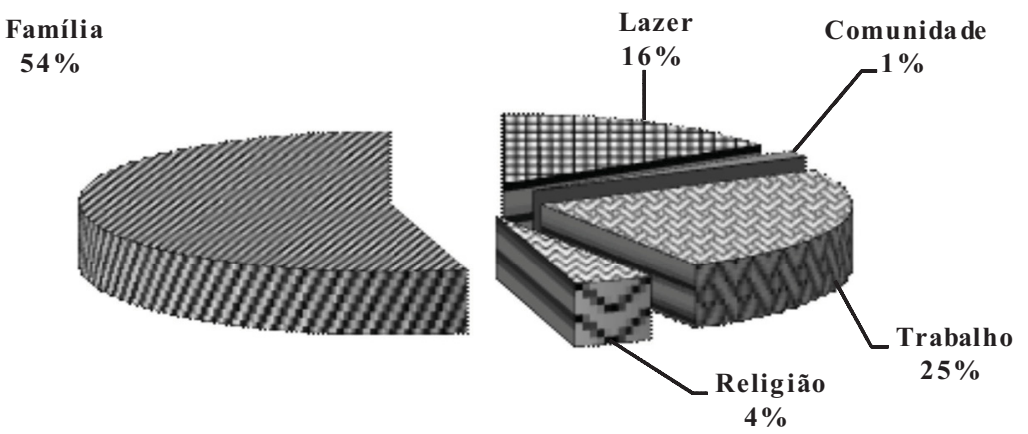

Figura 2

Importância de cada esfera da vida para a amostra geral.
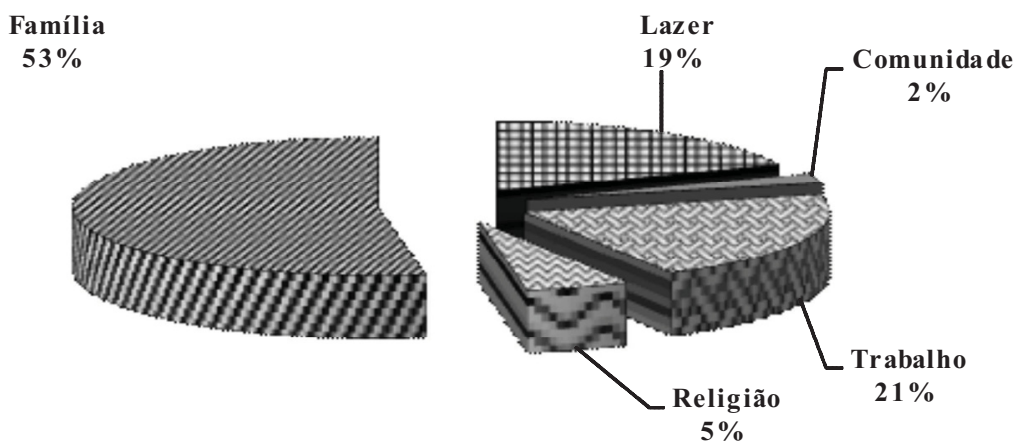

Figura 3

Importância de cada esfera da vida para os entrevistados pertencentes ao setor público.
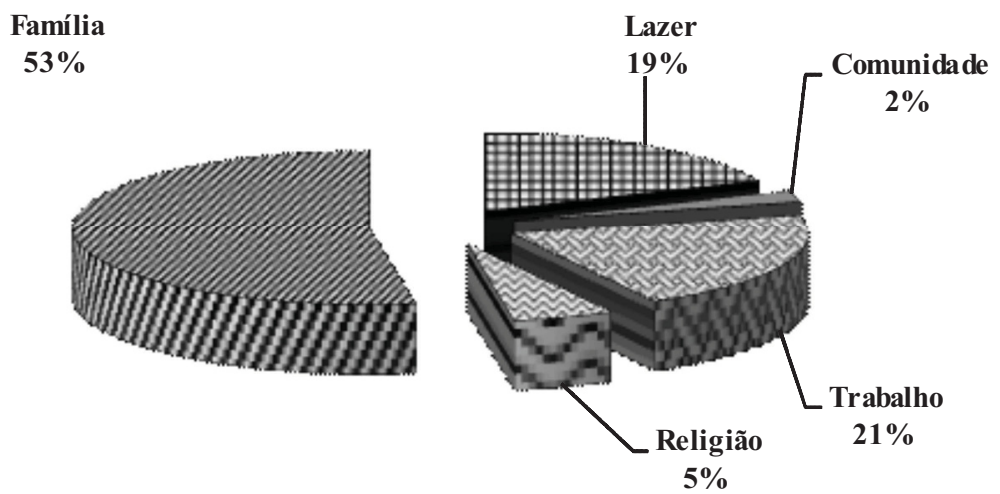

Figura 4

Importância de cada esfera da vida para os entrevistados pertencentes a outros setores da atividade econômica. 


\section{Significado do trabalho nos setores público e privado}

As Figuras 3 e 4 mostram que não há muita diferença entre o setor público e outros setores.

\subsection{Modelagem para o significado do trabalho}

Para o modelo proposto (MP) a exclusão de alguns indicadores seguiu alguns critérios: I) eliminar os indicadores com carga fatorial inferior a 0,7 ; II) eliminar no máximo um indicador por VL, por processamento; III) eliminar sempre o de menor carga fatorial; IV) não eliminar indicador de VL com somente dois indicadores; V) não descartar os indicadores das VLs de ordem superior a um. Após esses ajustes, chegou-se a um modelo que foi denominado de modelo final MP (Figura 5).

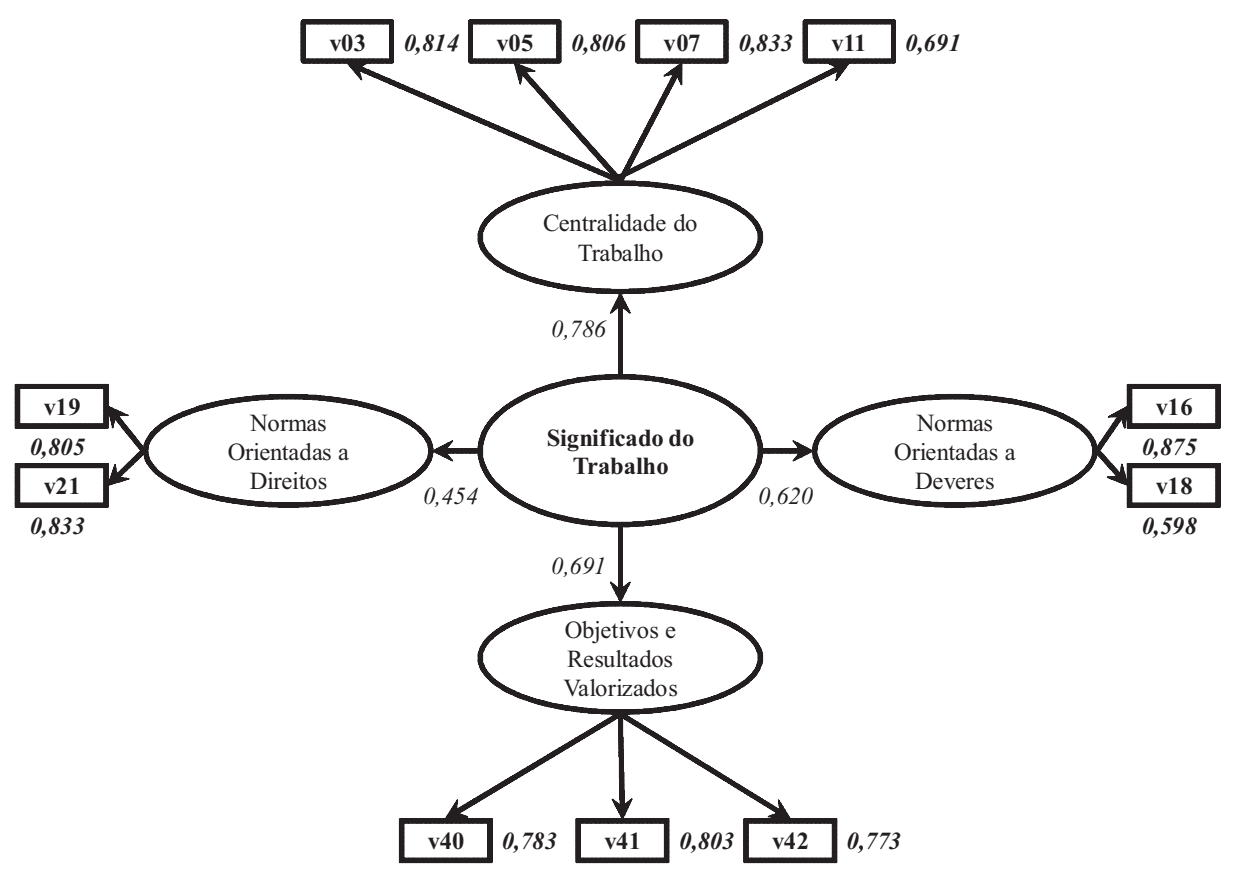

Figura 5

Construtos e variáveis do modelo final (MP), resultante do refinamento do modelo inicial.

A Tabela 3 exibe: AVE, alfa de Cronbach e confiabilidade composta do modelo final MP. 


\section{HuMANAs}

Tabela 3

Indicadores de qualidade do modelo final obtido: AVE e Confiabilidade composta.

\begin{tabular}{c|c|c|c|c}
\hline Variável Latente & Ordem & AVE & $\begin{array}{c}\text { Confiabilidade } \\
\text { Composta }\end{array}$ & $\begin{array}{c}\text { Alfa de } \\
\text { Cronbach }\end{array}$ \\
\hline $\begin{array}{c}\text { Centralidade do } \\
\text { Trabalho }\end{array}$ & $\mathbf{1}$ & 0,621 & 0,867 & 0,794 \\
\hline N.Orient. Deveres & $\mathbf{1}$ & 0,562 & 0,712 & 0,238 \\
\hline N.Orient. Direitos & $\mathbf{1}$ & 0,671 & 0,803 & 0,511 \\
\hline $\begin{array}{c}\text { Objet. Result. } \\
\text { Valorizados }\end{array}$ & $\mathbf{1}$ & 0,624 & 0,833 & 0,7 \\
\hline Significado do Trabalho & $\mathbf{2}$ & 0,39 & 0,711 & 0,705 \\
\hline
\end{tabular}

O construto Significado do Trabalho apresenta AVE 0,39, menor do que 0,5; portanto, sem validade convergente. Para os demais construtos o valor de AVE é maior que 0,5 , e a validade convergente é satisfeita. Quanto à confiabilidade composta, observam-se valores acima de 0,7 ; portanto, é atendida a condição de confiabilidade de escala.

Nas estatísticas referentes à validade discriminante, o modelo atendeu aos requisitos.

Quanto à estatística goodness of fit, o valor obtido foi de 0,44 .

Devido ao baixo valor da estatística goodness of fit e aos problemas destacados na Tabela 3, decidiu-se então analisar um modelo alternativo (MA) exibido na Figura 6.

O modelo MA apresenta os construtos: (nível 1) centralidade Kanungo, centralidade MOW, objetivos, resultados, normas orientadas a deveres e normas orientadas a direitos; (nível 2): centralidade do trabalho, normas sociais e objetivos e resultados valorizados; (nível 3): Significado do trabalho.

A Tabela 4 apresenta as estatísticas AVE e confiabilidade composta por construto do modelo MA.

Conforme a Tabela 4, os valores de AVE indicam validade convergente, embora o valor para Significado do trabalho $(0,484)$, esteja ligeiramente abaixo de 0,5 . Os valores da confiabilidade composta são todos superiores a 0,7 ; portanto, a confiabilidade de escala é satisfeita.

Como a raiz quadrada da AVE é maior que os valores das correlações com as demais VLs (Tabela 5) e os valores das cargas dos indicadores para as suas VLs são bem superiores que para as demais VLs (Tabela 6), confirma-se a validade discriminante. 
Significado do trabalho nos setores público e privado M.A. Gouvêa, S.H. Kubo \& D.M.N. Mantovani

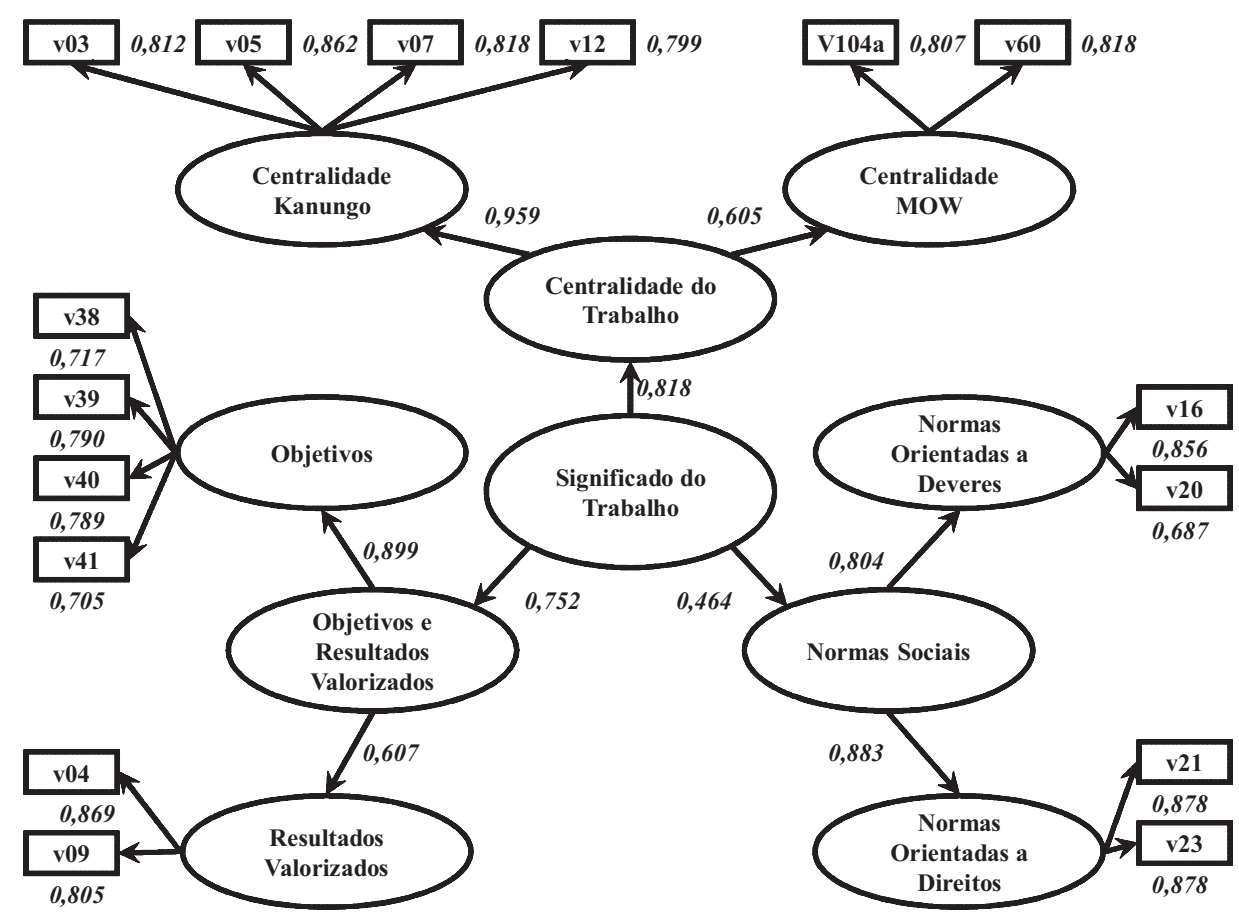

Figura 6

Construtos e variáveis do modelo alternativo (MA) desenvolvido para corrigir problemas de aderência identificados no modelo final (MP).

Tabela 4

Indicadores de qualidade para cada construto do modelo: AVE e Confiabilidade composta.

\begin{tabular}{l|l|r|c}
\hline Variável latente & Ordem & AVE & $\begin{array}{l}\text { Confiabilidade } \\
\text { Composta }\end{array}$ \\
\hline Centr.Kanungo & $\mathbf{1}$ & 0,677 & 0,894 \\
\hline Centr.MOW & $\mathbf{1}$ & 0,661 & 0,796 \\
\hline Centralidade do Trabalho & $\mathbf{2}$ & 0,642 & 0,774 \\
\hline N.Orient.Deveres & $\mathbf{1}$ & 0,603 & 0,750 \\
\hline N.Orient.Direitos & $\mathbf{1}$ & 0,771 & 0,871 \\
\hline Normas Sociais & $\mathbf{2}$ & 0,713 & 0,832 \\
\hline Objet.Result.Valorizados & $\mathbf{2}$ & 0,588 & 0,734 \\
\hline Objetivos & $\mathbf{1}$ & 0,564 & 0,838 \\
\hline Resultados & $\mathbf{1}$ & 0,701 & 0,824 \\
\hline Significado do Trabalho & $\mathbf{3}$ & 0,484 & 0,728 \\
\hline & & &
\end{tabular}

Revista de Ciências Humanas, Florianópolis, Volume 45, Número 2, p. 305-330, Outubro de 2011 
Tabela 5

Matriz de correlação das variáveis latentes do modelo alternativo.

\begin{tabular}{c|c|c|c|c|c|c}
\hline VL 1a ordem & $\begin{array}{c}\text { Centr. } \\
\text { Kanungo }\end{array}$ & $\begin{array}{c}\text { Centr. } \\
\text { MOW }\end{array}$ & $\begin{array}{c}\text { N.Orient. } \\
\text { Deveres }\end{array}$ & $\begin{array}{c}\text { N.Orient } \\
\text {. Direitos }\end{array}$ & $\begin{array}{c}\text { Objet. } \\
\text { Result. } \\
\text { Valorizados }\end{array}$ & Objetivos \\
\hline $\begin{array}{c}\text { Centr. } \\
\text { Kanungo }\end{array}$ & $\mathbf{0 , 8 2 3}$ & & & & & \\
\hline Centr. MOW & 0,354 & $\mathbf{0 , 8 1 3}$ & & & & \\
\hline $\begin{array}{c}\text { N.Orient. } \\
\text { Deveres }\end{array}$ & 0,135 & 0,111 & $\mathbf{0 , 7 7 6}$ & & & \\
\hline $\begin{array}{c}\text { N.Orient. } \\
\text { Direitos }\end{array}$ & 0,063 & 0,035 & 0,431 & $\mathbf{0 , 8 7 8}$ & & \\
\hline Objetivos & 0,135 & 0,129 & 0,256 & 0,086 & $\mathbf{0 , 7 5 1}$ & \\
\hline Resultados & 0,474 & 0,196 & 0,220 & 0,131 & 0,198 & $\mathbf{0 , 8 3 7}$ \\
\hline
\end{tabular}

Nota: A diagonal contém os valores das raízes de AVE.

Tabela 6.

Matriz de cargas (cross-loadings) para o modelo alternativo.

\begin{tabular}{c:c|c|c|c|c:c}
\hline & $\begin{array}{c}\text { Centr. } \\
\text { Kanungo }\end{array}$ & $\begin{array}{c}\text { Centr. } \\
\text { MOW }\end{array}$ & $\begin{array}{c}\text { N.Orient. } \\
\text { Deveres }\end{array}$ & $\begin{array}{c}\text { N.Orient. } \\
\text { Direitos }\end{array}$ & Resultados & Objetivos \\
\hline $\mathbf{v 0 3}$ & $\mathbf{0 , 8 1 2}$ & 0,281 & 0,155 & 0,034 & 0,445 & 0,149 \\
\hline $\mathbf{v 0 5}$ & $\mathbf{0 , 8 6 2}$ & 0,282 & 0,099 & 0,072 & 0,435 & 0,109 \\
\hline $\mathbf{v 0 7}$ & $\mathbf{0 , 8 1 8}$ & 0,281 & 0,155 & 0,069 & 0,283 & 0,131 \\
\hline $\mathbf{v 1 2}$ & $\mathbf{0 , 7 9 9}$ & 0,321 & 0,037 & 0,031 & 0,395 & 0,057 \\
\hline $\mathbf{v 6 0}$ & 0,291 & $\mathbf{0 , 8 1 8}$ & 0,138 & 0,062 & 0,188 & 0,108 \\
\hline $\mathbf{v 1 0 4 a}$ & 0,284 & $\mathbf{0 , 8 0 7}$ & 0,041 & $(0,006)$ & 0,129 & 0,101 \\
\hline $\mathbf{v 1 6}$ & 0,222 & 0,130 & $\mathbf{0 , 8 5 6}$ & 0,412 & 0,242 & 0,102 \\
\hline $\mathbf{v 2 0}$ & $0,056)$ & 0,026 & $\mathbf{0 , 6 8 7}$ & 0,235 & 0,074 & 0,341 \\
\hline $\mathbf{v 2 1}$ & 0,031 & 0,027 & 0,379 & $\mathbf{0 , 8 7 8}$ & 0,132 & 0,115 \\
\hline $\mathbf{v 2 3}$ & 0,080 & 0,034 & 0,378 & $\mathbf{0 , 8 7 8}$ & 0,097 & 0,036 \\
\hline $\mathbf{v 0 4}$ & 0,411 & 0,118 & 0,194 & 0,136 & $\mathbf{0 , 8 6 9}$ & 0,205 \\
\hline $\mathbf{v 0 9}$ & 0,382 & 0,220 & 0,173 & 0,078 & $\mathbf{0 , 8 0 5}$ & 0,120 \\
\hline $\mathbf{v 3 8}$ & 0,079 & 0,122 & 0,233 & 0,121 & 0,185 & $\mathbf{0 , 7 1 8}$ \\
\hline $\mathbf{v 3 9}$ & 0,125 & 0,105 & 0,113 & $(0,076)$ & 0,185 & $\mathbf{0 , 7 9 0}$ \\
\hline $\mathbf{v 4 0}$ & 0,090 & 0,020 & 0,187 & 0,080 & 0,075 & $\mathbf{0 , 7 8 9}$ \\
\hline $\mathbf{v 4 1}$ & 0,111 & 0,142 & 0,245 & 0,147 & 0,147 & $\mathbf{0 , 7 0 5}$ \\
\hline & & & & & &
\end{tabular}

O modelo MA apresenta o resultado 0,589 para a estatística goodness of fit, que é melhor valor do que o do modelo MP. Comparando-se os dois modelos, MA é adotado como o modelo final deste estudo. Quanto às hipóteses do estudo, houve confirmação das três primeiras, de acordo com a Figura 6: 
$\mathrm{H}_{1}$ : A centralidade no trabalho é o aspecto mais relevante na composição do construto significado do trabalho (coeficiente 0,818 ).

$\mathrm{H}_{2}$ : Os objetivos e resultados valorizados são o segundo aspecto mais relevante na composição do construto significado do trabalho (coeficiente 0,752 ). $\mathrm{H}_{3}$ : As normas sociais são o terceiro aspecto mais relevante (coeficiente 0,464$)$.

Adotando-se o modelo MA e separando-se a amostra em duas sub-amostras, relativas aos setores público e privado, foi novamente processada a técnica de modelagem de equações estruturais.

As Figuras 7 e 8 exibem os modelos finais em cada setor, após a remoção dos indicadores com cargas fatoriais estatisticamente não significantes.

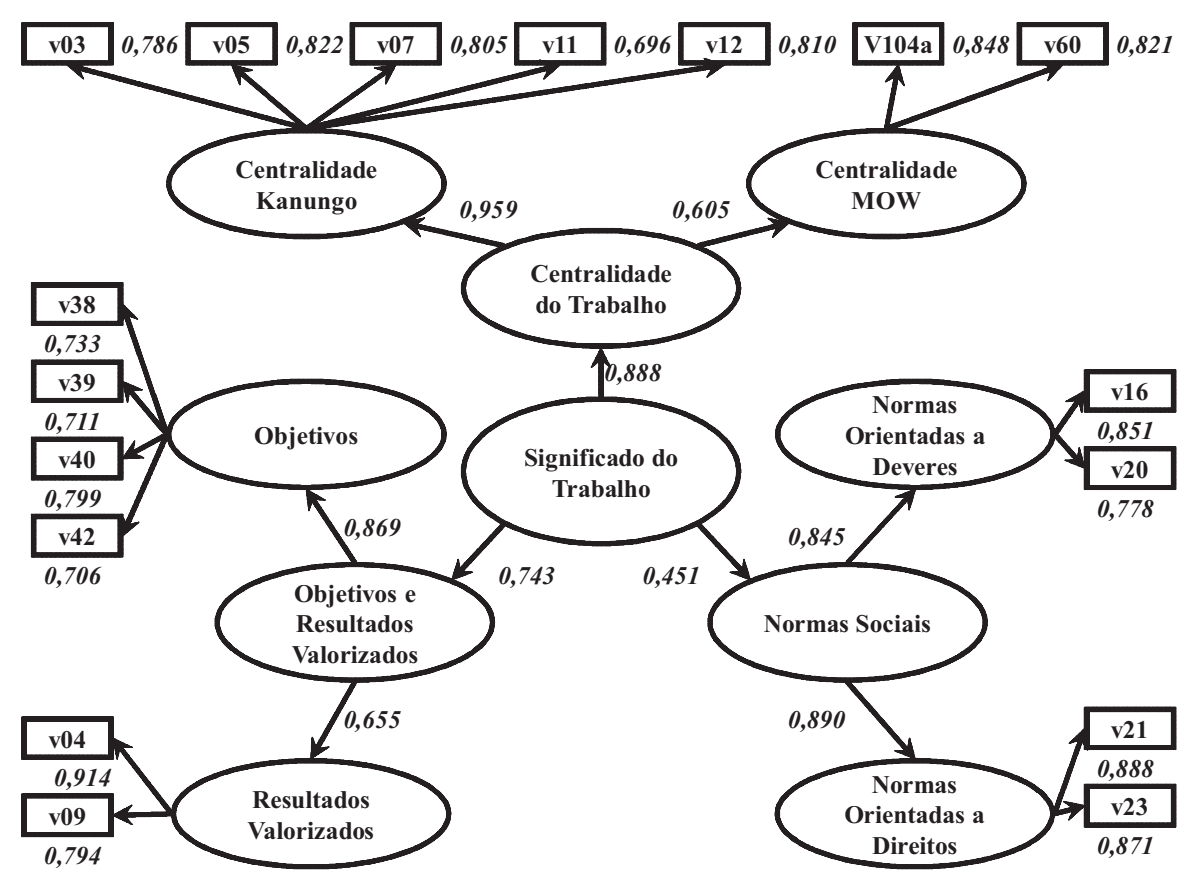

Figura 7

Construtos e variáveis do modelo final para o Setor público. 
UMANAS

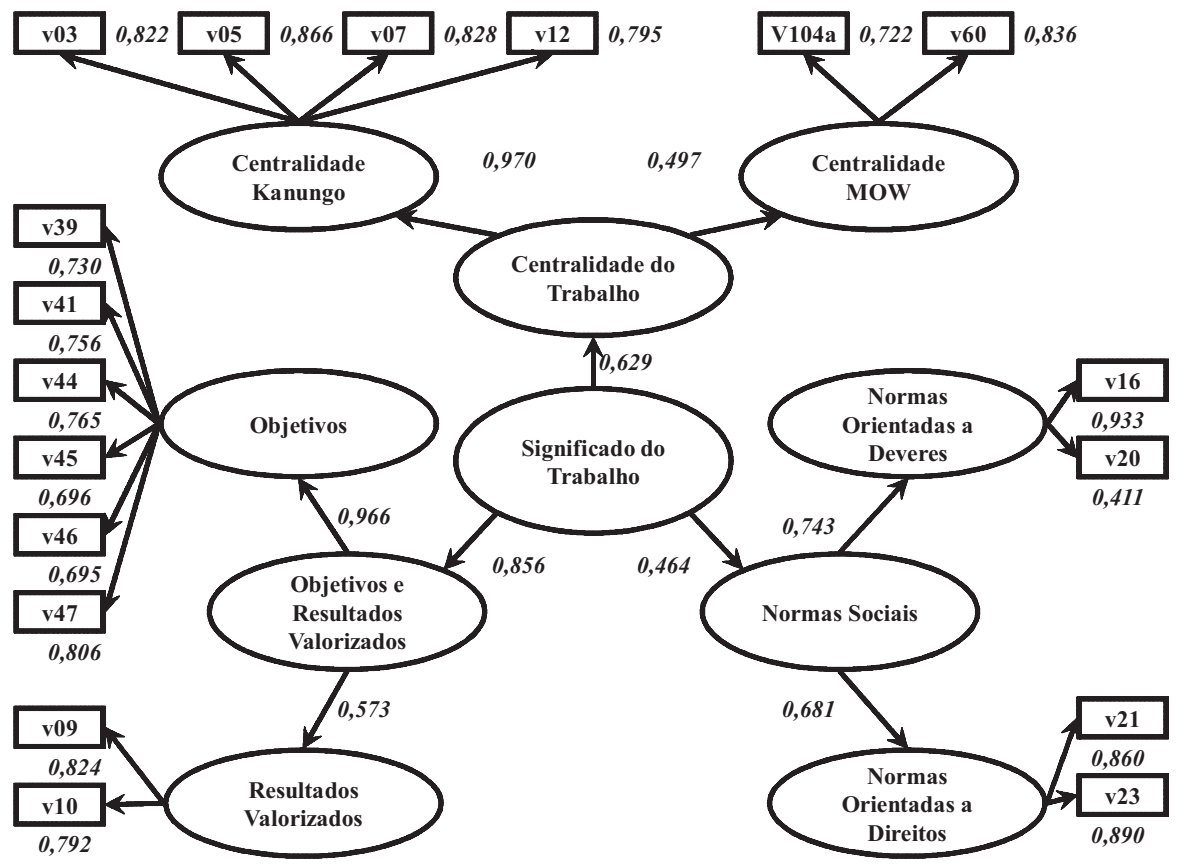

Figura 8

Construtos e variáveis do modelo final para o Setor privado.

A Tabela 7 apresenta a estatística de qualidade de ajuste dos modelos aos dados da amostra.

Tabela 7

Ajuste do modelo Goodness of fit.

\begin{tabular}{|l|r|l|l|}
\hline & Geral & $\begin{array}{l}\text { Setor } \\
\text { Público }\end{array}$ & $\begin{array}{l}\text { Outros } \\
\text { Setores }\end{array}$ \\
\hline Goodness of fit & 0,589 & 0,607 & 0,564 \\
\hline
\end{tabular}

Pode-se dizer, considerando-se os valores de goodness of fit dos modelos, que o modelo que está ligeiramente mais aderente aos dados de sua amostra é o do Setor público.

De acordo com as Figura 7 e 8, foram confirmadas as hipóteses 4, 5, 6 e 9: 


\section{Significado do trabalho nos setores público e privado}

$\mathrm{H}_{4}$ : A centralidade no trabalho é o aspecto mais relevante na composição do construto significado do trabalho no setor público (coeficiente 0,888 ). $\mathrm{H}_{5}$ : Os objetivos e resultados valorizados são o segundo aspecto mais relevante na composição do construto significado do trabalho no setor público (coeficiente 0,743 ).

$\mathrm{H}_{6}$ : As normas sociais são o terceiro aspecto mais relevante na composição do construto significado do trabalho no setor público (coeficiente 0,451 ). $\mathrm{H}_{7}$ : A centralidade no trabalho é o aspecto mais relevante na composição do construto significado do trabalho em outros setores (coeficiente 0,629 ). A centralidade foi considerada o segundo aspecto mais relevante. $\mathrm{H}_{8}$ : Os objetivos e resultados valorizados são o segundo aspecto mais relevante na composição do construto significado do trabalho em outros setores (coeficiente 0,856 ).

Os objetivos e resultados valorizados foram considerados o primeiro aspecto mais relevante.

$\mathrm{H}_{9}$ : As normas sociais são o terceiro aspecto mais relevante na composição do construto significado do trabalho em outros setores (coeficiente 0,464$)$.

A Tabela 8 apresenta os indicadores mantidos em cada construto na amostra geral e nas duas sub-amostras. Essa comparação fornece, para cada subamostra, os indicadores que melhor refletem as características dos respondentes. Serão destacadas as diferenças nas sub-amostras em relação à amostra total.

Analisando o Setor Público, pode ser observado que há valorização do indicador (v11) Trabalho como Sentido da Vida, na Centralidade de Kanungo (1982). Nos Objetivos, o Setor Público não vê necessidade da (v41) Tarefa adequada à capacidade; por outro lado, necessita de (v42) Variedade.

Na sub-amostra de Outros Setores, não são enfatizados os objetivos de (v38) Aprender Coisas Novas, nem da (v40) Autonomia. Entretanto, são relevantes o (v44) Ambiente Físico do Trabalho, o (v45) Bom Relacionamento Interpessoal, o (v46) Trabalho interessante e o (v47) Bom Salário. Por outro lado, nesta sub-amostra, não se reconhece (v04) Contatos Interessantes como Resultado valorizado, mas espera-se que o trabalho seja interessante e satisfatório (v10). 





Significado do trabalho nos setores público e privado M.A. Gouvêa, S.H. Kubo \& D.M.N. Mantovani
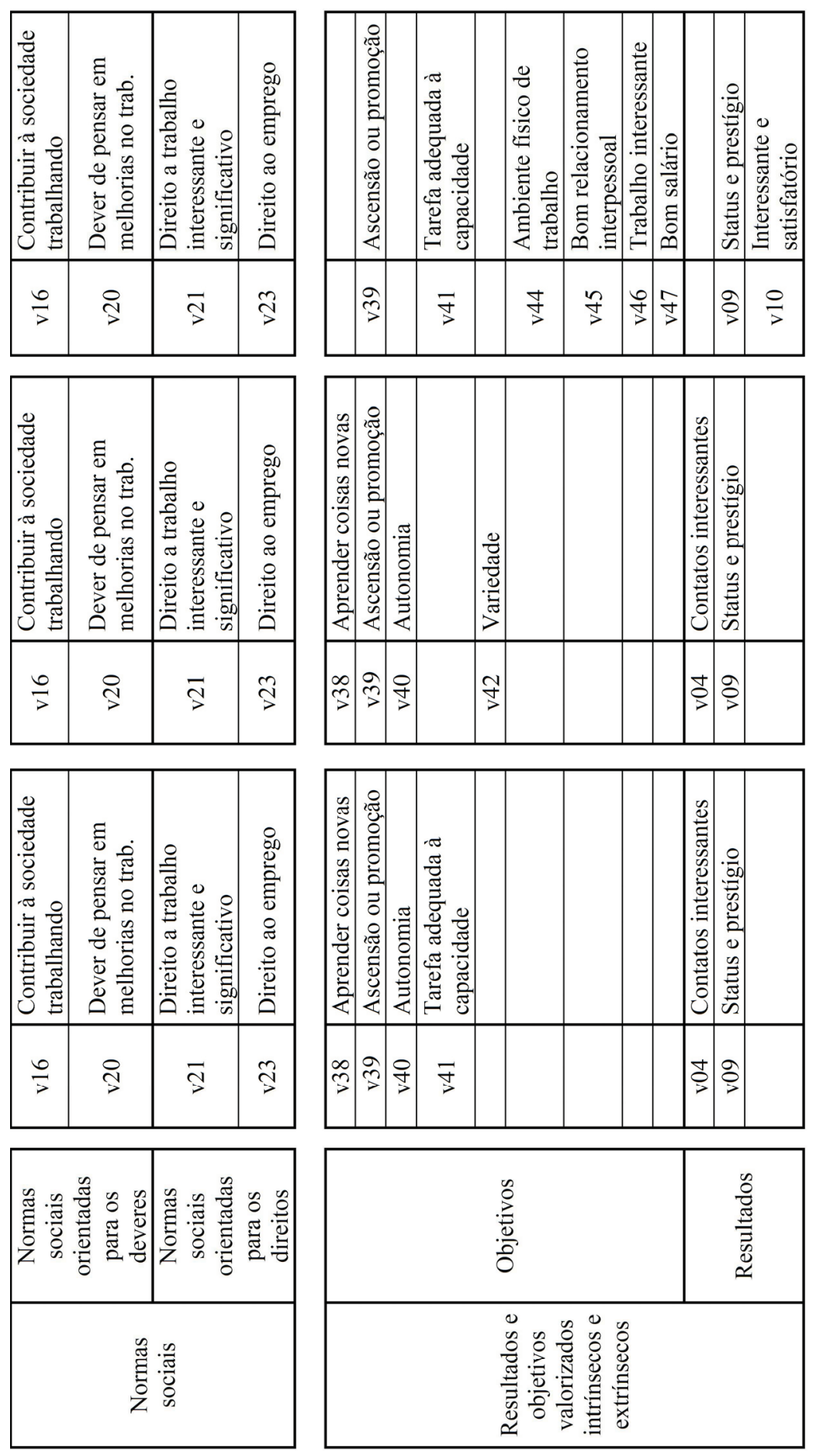

Revista de Ciências Humanas, Florianópolis, Volume 45, Número 2, p. 305-330, Outubro de 2011 


\section{Conclusões}

Este estudo foi desenvolvido com o objetivo de identificação dos aspectos mais associados ao significado do trabalho na vida das pessoas. Complementarmente, buscou-se conhecer os indicadores mais relevantes nos segmentos de setor público e privado.

Com a aplicação da modelagem de equações estruturais, verificou-se que na amostra geral e no setor público o significado do trabalho se reflete, na ordem, na centralidade do trabalho, objetivos e resultados valorizados e por último, nas normas sociais. Há uma inversão na segunda e terceira colocação deste ranking quando se focaliza o setor privado.

Focalizando-se os indicadores dentro de cada construto dos respectivos modelos sobre o significado do trabalho, tem-se que houve convergência de resultados no construto normas sociais e muita semelhança nos indicadores referentes à centralidade do trabalho. Os contrastes encontrados nas duas subamostras são mais nítidos no construto resultados e objetivos valorizados.

Espera-se que o conhecimento dos aspectos que conferem sentido ao trabalho, em cada um dos setores específicos pesquisados neste estudo, seja uma ferramenta útil para a atuação das áreas de recursos humanos, tanto da administração pública como de empresas privadas, com a finalidade de promover programas de incentivo e motivação e de melhorar o desempenho desses funcionários, com o conseqüente benefício de todos os agentes envolvidos nas relações de trabalho e da empresa como um todo.

\section{Referências bibliográficas}

BASTOS, A.V.B. et al. Significado do trabalho: um estudo entre trabalhadores inseridos em organizações formais. Revista de Administração de Empresas, $35: 20-29,1995$.

BRESSER-PEREIRA, L.C. Burocracia pública e classes dirigentes no Brasil. Revista de Sociologia e Política, 28: 9-30, 2007.

CARMO, P.S. A ideologia do trabalho. São Paulo: Moderna, 2001.

CHIN, W.W. The partial least squares approach for structural equation modeling. In: G.A. Marcoulides (Ed.). Modern Methods for Business Research. Nova York: Psychology Press, 1998.

FONSECA, G.F. Em Busca do Significado do Trabalho: um estudo qualitativo entre gerentes. Dissertação de Mestrado. São Paulo: Universidade de São Paulo, 2000. 


\section{Significado do trabalho nos setores público e privado}

M.A. Gouvêa, S.H. Kubo \& D.M.N. Mantovani

FORNELL, C. \& LARCKER, D.F. Evaluating structural equation models with unobservable variables and measurement error. Journal of Marketing Research, 18:39-50, 1981.

GOMES, C.L. Lazer, trabalho e educação. Belo Horizonte: Editora da UFMG, 2008.

GRAZIA, S. Tiempo, trabajo y ócio. Madri: Tecnos, 2000.

HAIR Jr., J. et al. Análise Multivariada de Dados. Porto Alegre: Artmed, 2005.

HARPAZ, I. \& FU, X. The structure of meaning of work: a relative stability amindst change. Human relations, 55: 639-67, 2002.

KANUNGO, R.N. Measurement of job and work involvement. Journal of Applied Psychology, 67(3): 341-49, 1982.

LUNDBERG, C.D. \& PETERSON, M.F. The Meaning of Working in U.S. and Japanese Local Governments at Three Hierarchical Levels. Human Relations, 47(12): 1459-87, 1994.

MORIN, E.M. Meaning of work in modern times. Rio de Janeiro: Anais do World Congress on Human Resources Management, 2004. Documento em PDF: http:/ /web.hec.ca/criteos/fichiers/upload/MOW_in_MTimes_EMM200804.pdf(acesso: 11 de Dezembro de 2011.

MOW - International Research Team. Londres: Academic Press, 1987.

NAKAGAWA, S.S.Y. A lealdade de consumidores nos ambientes de comércio online e offline. Tese de Doutoramento. São Paulo: Universidade de São Paulo, 2008.

PÉREZGONZÁlEZ, J.D. \& VILELA, L.D. La Centralidad Del Trabajo. Dublin: Lulu inc., 2005.

RINGLE, C.M.; WENDE, S. \& WILL, S. (2005). SmartPLS 2.0 (M3) Beta [Software]. Hamburg, Germany. Disponível em: http://www.smartpls.de (acesso: 1 Agosto de 2008).

SECRETARIA DE GESTÃO PÚBLICA. As políticas de gestão e de recursos humanos 2003-2006 - Relatório. São Paulo, SP.

SIEBRA, L.M.G. Significado do trabalho: um estudo entre trabalhadores do setor turístico no estado do Ceará. Dissertação de Mestrado. São Paulo: Universidade de São Paulo, 2000. 


\section{HUMANAS}

SOARES, C.R.V. Significado do trabalho: um estudo comparativo de categorias ocupacionais. Dissertação de Mestrado. Brasília: Universidade de Brasília, 1992.

SON, S. Defining the meaning of work for minority older adults: a comparative study between Korean Americans and African Americans. Doctoral Dissertation Nova York: Columbia University, 2006.

ZWICKER, R.; SOUZA, C.A. \& BIDO, D. de S. Uma revisão do modelo do grau de informatização de empresas: novas propostas de estimação e modelagem usando PLS (partial least squares). Rio de Janeiro: Anais do Encontro Nacional da Associação Nacional de Pós-Graduação e Pesquisa em Administração - ANPAD, 2008. 